\title{
SCADA FOR PROTOTYPE OF DOUBLE TRACK RAILROAD GATE ARM AUTOMATION BASED ON PLC M221
}

\author{
Theresia Prima Ari Setiyani ${ }^{1)}$, Dede Kurniawan Salim ${ }^{2)}$ \\ Teknik Elektro, Universitas Sanata Dharma \\ Paingan, Maguwoharjo, Depok, Sleman \\ Email: 1 ariprima@usd.ac.id
}

\begin{abstract}
Most of the gate arm at railroad crossings in Indonesia still using manual systems. Operator error and failure of a manual gate arm operate are factors in the occurrence of accidents on the railroad crossing. SCADA for railroad gate arm is an automation control system to open and close a railroad gate arm that has 2 lanes (double track). The system uses a PLC Schneider M221 as a controller and an HMI as an interface. The HMI allows operators to monitor system conditions in real-time. Four pairs of photosensors on the right and left side of the gate arm are used to detect trains in each lane. Information from the photosensor is processed by the PLC to control the gate arm motor, buzzer, indicator lights, and information display to the HMI. There are 2 operation modes, automatic and manual. In automatic mode, when the photosensor detects a train is about to pass, the gate arm closes, the buzzer goes on, the red light flashes. After the photosensor detects that the train has passed, the gate arm will open, the buzzer will off, and the green light will off. if the photosensor are damaged then manual operation mode is using by pressing the open or close button.
\end{abstract}

Keywords : SCADA, PLC, railroad gate, double track, HMI

\section{Pendahuluan}

Kereta api merupakan salah satu sarana transportasi darat yang masih aktif dan diminati oleh masyarakat [1]. Dalam operasionalnya tidak dapat dihindari bahwa rel kereta pasti bersinggungan dengan jalan raya, sehingga keamanan pada perlintasan menjadi hal penting yang harus diperhatikan. Palang pintu pada perlintasan kereta api di Indonesia masih menggunakan sistem manual sehingga masih diperlukan operator untuk membuka tutup palang pintu kereta api [2]. Kesalahan operator dan gagalnya palang pintu manual beroperasi menjadi salah satu faktor terjadinya kecelakaan pada palang pintu lintasan kereta api. Sistem pintu pintu perlintasan kereta api secara manual umumnya bekerja sebagai berikut: ketika operator pengendali menerima sinyal bahwa akan ada kereta api yang melewati penyeberangan maka operator akan segera menurunkan palang pintu untuk menutup jalan penyeberangan bagi bus/ motor atau pejalan kaki dan membiarkan kereta api melewati penyeberangan dengan leluasa. Setelah kereta api melintas sepenuhnya maka operator akan menaikkan palang pintu untuk membuka jalan bagi bus/ motor dan pejalan kaki [2]. Demikian secara berulang- ulang operator melaksanakan pengendalian palang pintu penyeberangan.

SCADA (Supervisory Control And Data Acquisition) merupakan teknologi otomasi berbasis komputer yang digunakan untuk monitoring dan kontroling suatu sistem. Biasanya SCADA digunakan untuk melakukan monitoring dan kontroling proses industri yang kompleks menggantikan tenaga manusia (bisa karena dianggap berbahaya atau tidak praktis) dan biasanya merupakan proses-proses yang melibatkan faktor-faktor kontrol yang lebih banyak, faktor-faktor 
kontrol gerakan-cepat yang lebih banyak, dan lain sebagainya, dimana pengontrolan oleh manusia menjadi tidak nyaman lagi [3].

SCADA untuk palang pintu KA merupakan sistem otomasi pengendalian buka tutup palang pintu KA yang memiliki 2 jalur (double track). Sistem menggunakan PLC ( Programmable Logic Controller) dari Schneider M221 sebagai kontroler dan HMI ( Human Machine Interface ) sebagai interface. Adanya HMI akan mempermudah operator untuk mengatur dan melihat kondisi sistem secara real time. Penggunaan PLC sebagai kontroler adalah karena PLC memiliki beberapa kelebihan dibanding sistem kontrol konvensional seperti sistem pengkabelan lebih sederhana, pemrograman ulang relatif cepat, adanya record data dan interface yang memudahkan pengguna serta kemudahan pengecekan kerusakan [4]. Penggunaan PLC Schneider seri M221 adalah karena PLC seri tersebut memiliki port ethernet sehingga memungkinkan pemantauan dari jarak jauh melalui internet[5].

Beberapa penelitian tentang otomasi palang pintu KA sudah ada sebelumnya antara lain, Miniatur Palang Pintu Kereta Api Otomatis dengan Menampilkan Kecepatan Kereta Serta Waktu Tunggu Menggunakan Arduino [6], Palang Pintu Kereta Otomatis dengan Indikator Suara Sebagai Peringatan Dini Berbasis Mikrokontroler AT89S51 [7], Sistem PLC Pada Model Pengatur Palang Pintu Perlintasan Kereta Api Otomatis [8]. Namun penelitian tersebut hanya menggunakan 1 jalur kereta dan belum menggunakan sistem SCADA.

\section{Metodelogi Penelitian}

Diagram blok yang digunakan dalam penelitian ini adalah seperti gambar 1 berikut :

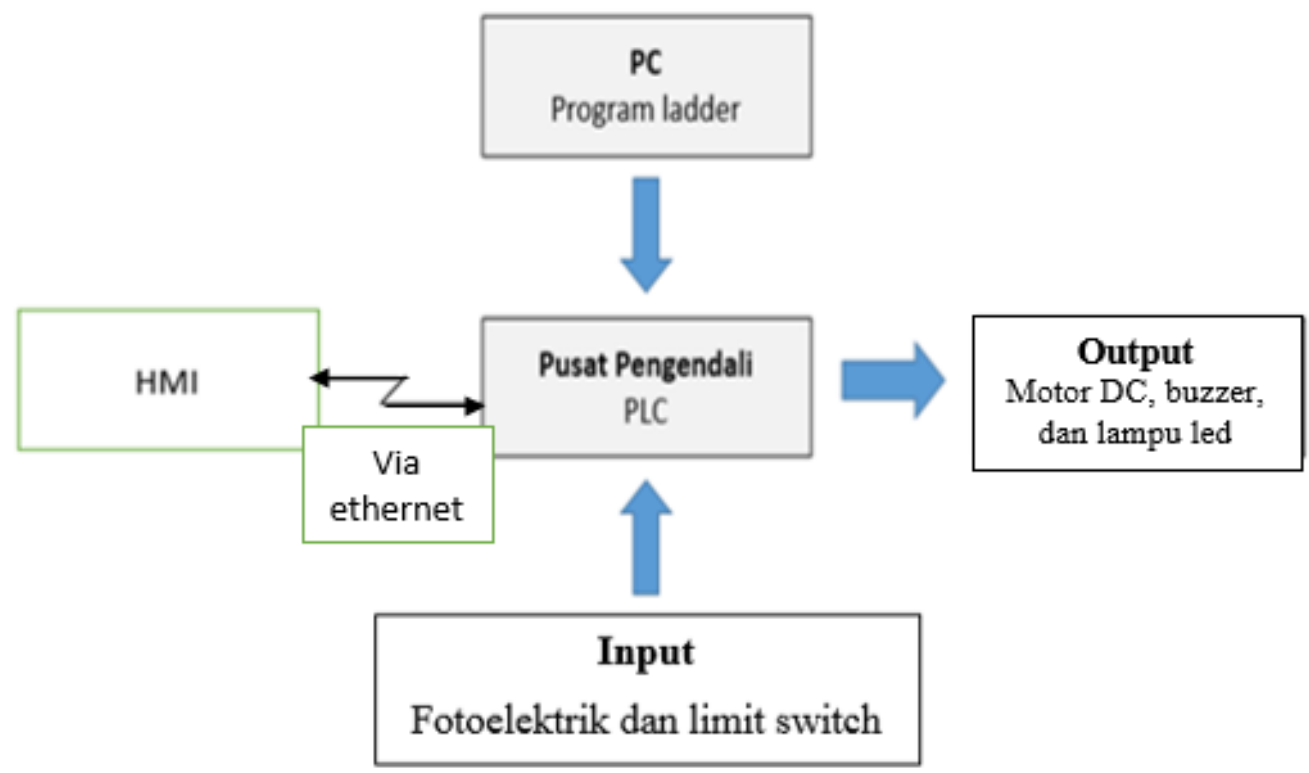

Gambar 1. Diagram blok SCADA untuk prototipe palang pintu kereta api otomatis 2 jalur berbasis PLC M221

Dengan demikian metode penelitian yang digunakan yaitu :

a. Perancangan dan implementasi perangkat keras prototipe rel kereta api, yang meliputi sistem sensor, motor penggerak palang pintu KA, sistem alarm, dan lampu indikator. Komponen elektronis yang digunakan dapat dilihat pada Tabel 1. 
Tabel 1. Komponen elektronik prototipe palang pintu kereta api otomatis 2 jalur

\begin{tabular}{|c|l|l|}
\hline No. & \multicolumn{1}{|c|}{ Keterangan } & \multicolumn{1}{c|}{ Fungsi atau keterangan } \\
\hline 1 & Fotosensor 1 & Mendeteksi kereta melintas. \\
\hline 2 & Fotosensor 2 & Mendeteksi kereta melintas. \\
\hline 3 & Fotosensor 3 & Mendeteksi kereta melintas. \\
\hline 4 & Fotosensor 4 & Mendeteksi kereta melintas. \\
\hline 5 & Limit switch 1 & Sebagai pembatas palang pintu 1 saat naik. \\
\hline 6 & Limit switch 2 & Sebagai pembatas palang pintu 1 saat turun. \\
\hline 7 & Limit switch 3 & Sebagai pembatas palang pintu 2 saat naik. \\
\hline 8 & Limit switch 4 & Sebagai pembatas palang pintu 2 saat turun. \\
\hline 9 & Push Button naik & Membuka palang pintu 1\&2 secara manual. \\
\hline 10 & Push Button turun & Menutup palang pintu 1\&2 secara manual. \\
\hline 11 & Led Merah 1 & $\begin{array}{l}\text { Sebagai indikator bahwa pengguna jalan raya } \\
\text { sisi utara tidak boleh melintas. }\end{array}$ \\
\hline 12 & Led Merah 2 & $\begin{array}{l}\text { Sebagai indikator bahwa pengguna jalan raya } \\
\text { sisi selatan tidak boleh melintas. }\end{array}$ \\
\hline 13 & Led Hijau 1 & $\begin{array}{l}\text { Sebagai indikator bahwa pengguna jalan raya } \\
\text { sisi utara boleh melintas. }\end{array}$ \\
\hline 14 & Led Hijau 2 & $\begin{array}{l}\text { Sebagai indikator bahwa pengguna jalan raya } \\
\text { sisi selatan boleh melintas. }\end{array}$ \\
\hline 15 & Buzzer & Sebagai indikator bahwa kereta akan melintas. \\
\hline 16 & Motor DC Palang Pintu 1 & Sebagai penggerak palang pintu 1. \\
\hline 17 & Motor DC Palang Pintu 2 & Sebagai penggerak palang pintu 2. \\
\hline
\end{tabular}

b. Perancangan dan implementasi perangkat lunak yang meliputi pemrograman ladder PLC untuk kendali motor palang pintu KA, alarm dan lampu indikator, serta HMI untuk animasi palang pintu kereta dan informasi status sensor, alarm dan lampu indikator. Programing PLC menggunakan perangkat lunak SoMachine Basic, sedangkan Programing HMI menggunakan perangkat lunak Wonderware InTouch

c. Perancangan dan implementasi konfigurasi jaringan Ethernet menggunakan Wonderware MODBUS Ethernet I/O Server (MBENET). MBENET adalah program aplikasi Microsoft Windows yang memungkinkan akses data di PLC Modicon melalui jaringan Ethernet ke PC sehingga layar monitor - sebagai HMI - dapat menampilkan informasi sistem secara real time. Protokol komunikasi melalui Ethernet digunakan untuk menangani elemen data dalam percakapan yang menggunakan konvensi penamaan tiga bagian yang mencakup application name, Topic Name, dan Item Name.

d. Uji coba dan pengambilan data untuk menguji prototipe dan HMI yang sudah dibuat sehingga dapat dilihat hasil kerjanya. Data yang diambil berupa data respon sistem saat kereta melintas dari barat dan timur, baik 1 jalur maupun 2 jalur. Kemudian membandingkan respon pada prototipe tersebut dengan indikator sensor, alarm, buzer dan proses animasi pada HMI.

e. Analisis dan penyimpulan hasil percobaan. Analisis data dilakukan dengan membandingkan keakuratan proses pada prototipe dengan animasi pada HMI sehingga dapat diambil kesimpulan tentang berhasil tidaknya sistem yang dibuat. 


\section{Hasil dan Pembahasan}

Hasil implementasi perangkat keras prototipe jalur rel kereta api, yang meliputi sistem sensor, motor penggerak palang pintu KA, sistem alarm, dan lampu indikator, dapat dilihat pada gambar 2 berikut.

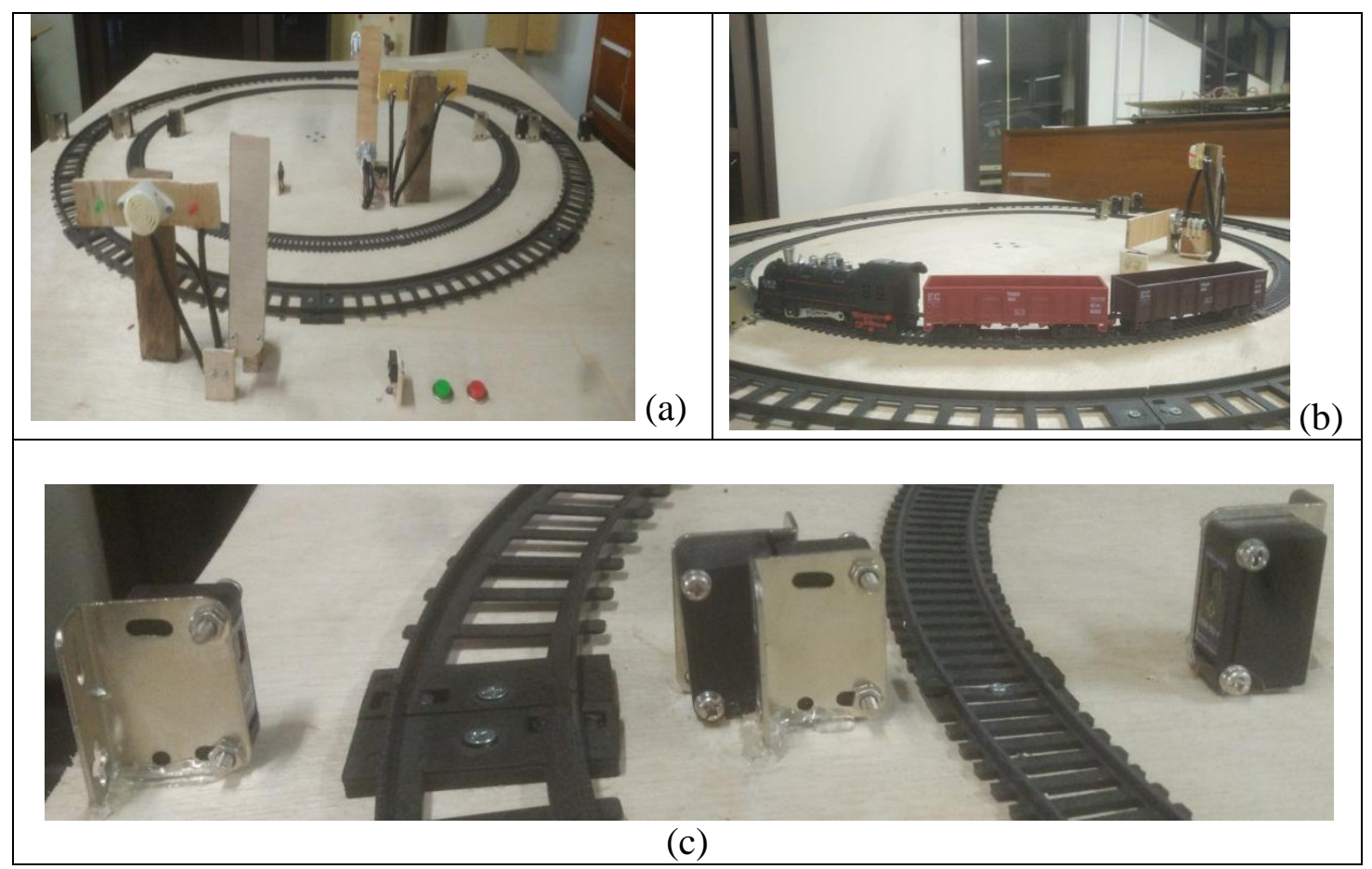

Gambar 2. (a). Hasil implementasi prototype sistem. (b). Kondisi saat sebuah KA melintas. (c). Posisi pemasangan foto sensor

HMI ditampilkan melalui layar monitor. Hasil tampilan HMI beserta keterangannya dapat dilihat pada Gambar 3 dan Tabel 2 berikut.

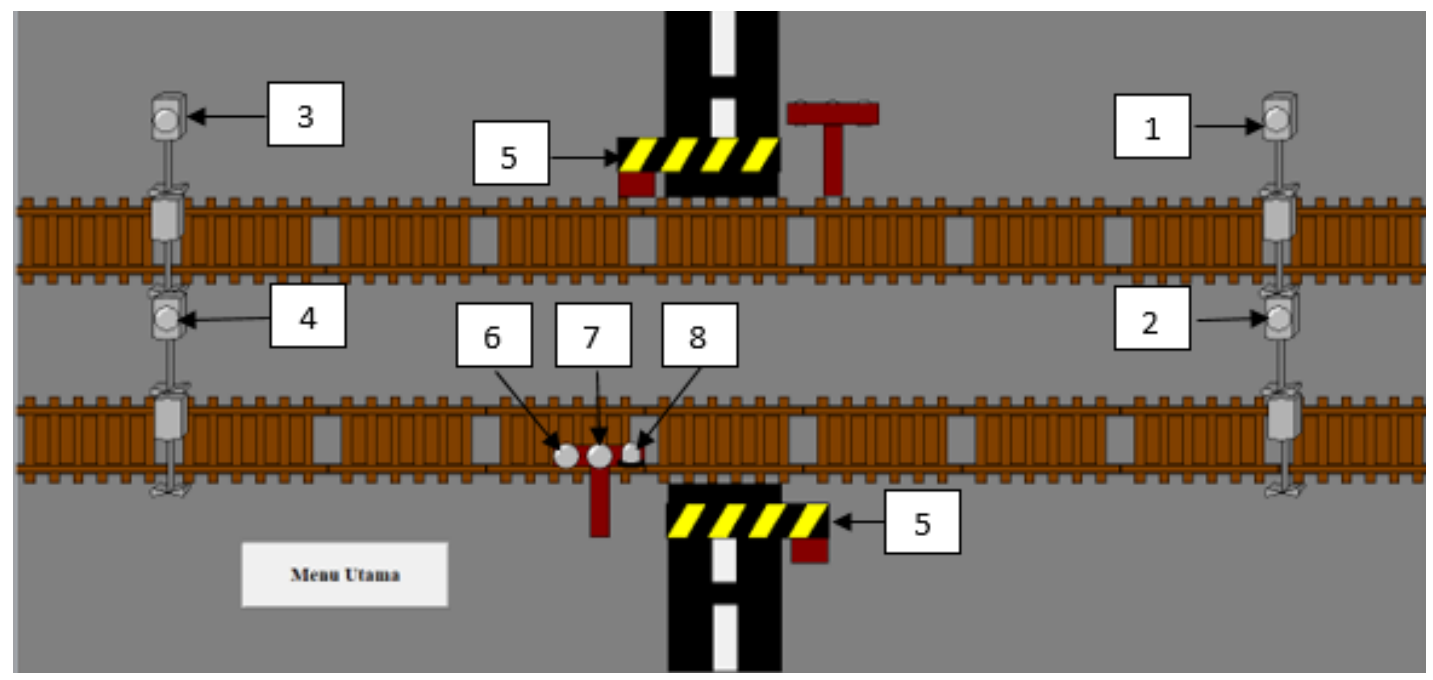

Gambar 3. Tampilan menu monitoring HMI 
Tabel 2. Keterangan tampilan HMI menu monitoring

\begin{tabular}{|c|c|c|c|}
\hline No & Keterangan & No & Keterangan \\
\hline 1 & Foto sensor 1 & 5 & Palang pintu \\
\hline 2 & Foto sensor 2 & 6 & Led merah \\
\hline 3 & Foto sensor 3 & 7 & Led hijau \\
\hline 4 & Foto sensor 4 & 8 & Buzzer / Alarm \\
\hline
\end{tabular}

Sistem telah diuji coba dan berhasil diaplikasikan untuk KA dengan berbagai macam jumlah gerbong, yaitu $0 \mathrm{~s} / \mathrm{d} 3$, dengan berbagai macam kondisi sebagai berikut:

a. $1 \mathrm{KA}$ melintas dari kiri ke kanan dan sebaliknya pada jalur atas.

b. 1 KA melintas dari kiri ke kanan dan sebaliknya pada jalur bawah.

c. 2 KA melintas bersamaan dari kanan semua

d. 2 KA melintas bersamaan dari kiri semua

e. 2 KA melintas bersamaan dari kanan dan kiri

f. 2 KA melintas berurutan dari kanan semua

g. 2 KA melintas berurutan dari kiri semua

h. 2 KA melintas berurutan dari kanan dan kiri

Dari pengamatan saat uji coba dapat diamati bahwa pada mode otomatis kondisi awal diasumsikan tidak ada KA yang akan melintas, sehingga palang pintu dalam kondisi terbuka, lampu indikator hijau menyala, lampu indikator merah mati dan buzzer tidak berbunyi. Saat foto sensor mendeteksi adanya KA yang akan melintas di persimpangan, maka palang pintu akan mulai menutup, lampu indikator hijau mati, lampu indikator merah hidup berkedip dan buzzer berbunyi. Saat foto sensor mendeteksi gerbong terakhir KA telah melintas di persimpangan, maka palang pintu akan mulai membuka, lampu indikator hijau hidup, lampu indikator merah mati dan buzzer berhenti berbunyi. Beberapa tampilan di HMI untuk kondisi KA datang dari Arah Timur Melalui Jalur Utara mulai dari kondisi awal - proses penutupan palang sampai pembukaan palang dapat dilihat pada Tabel 3 .

Tabel 3. Data Tampilan HMI dan Komponen Proses Kereta Datang dari Arah Timur Melalui Jalur Utara

Ket : 1=ON; 0=OFF; FE=Fotosensor; MDC=Motor DC; LM=Led Merah; LH=Led Hijau; $\mathrm{Buz}=$ Buzzer

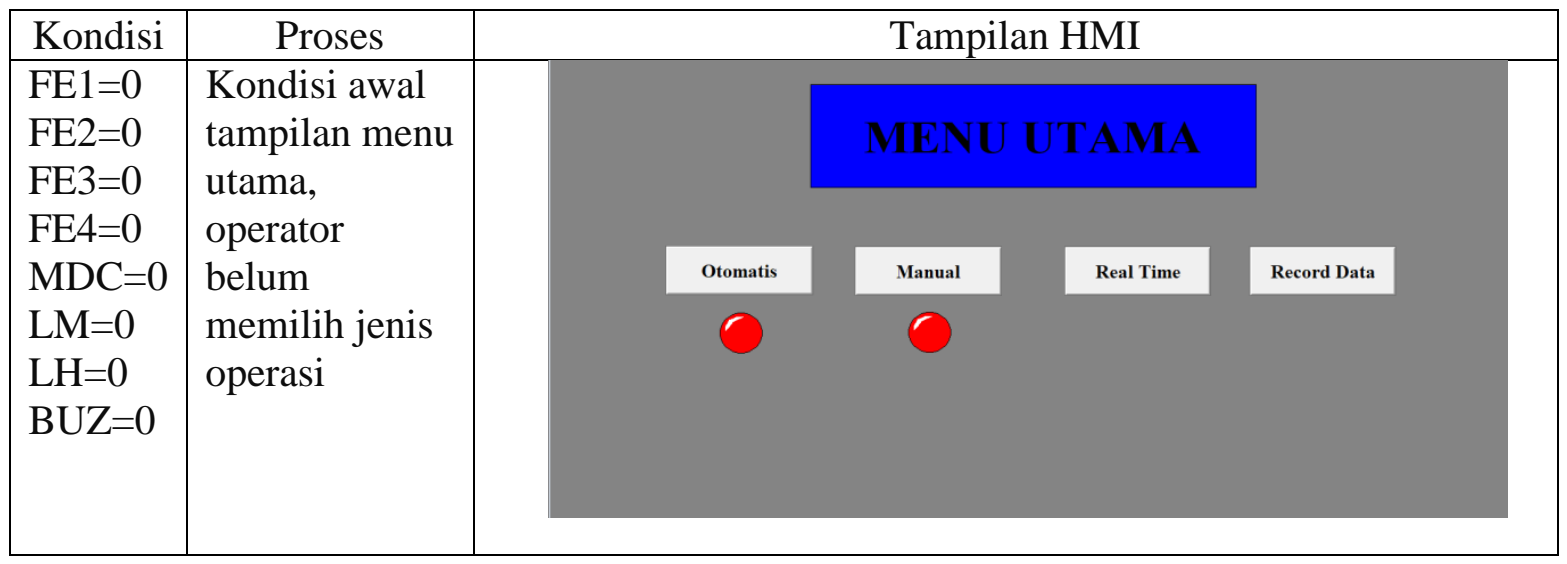


Lanjutan Tabel 3

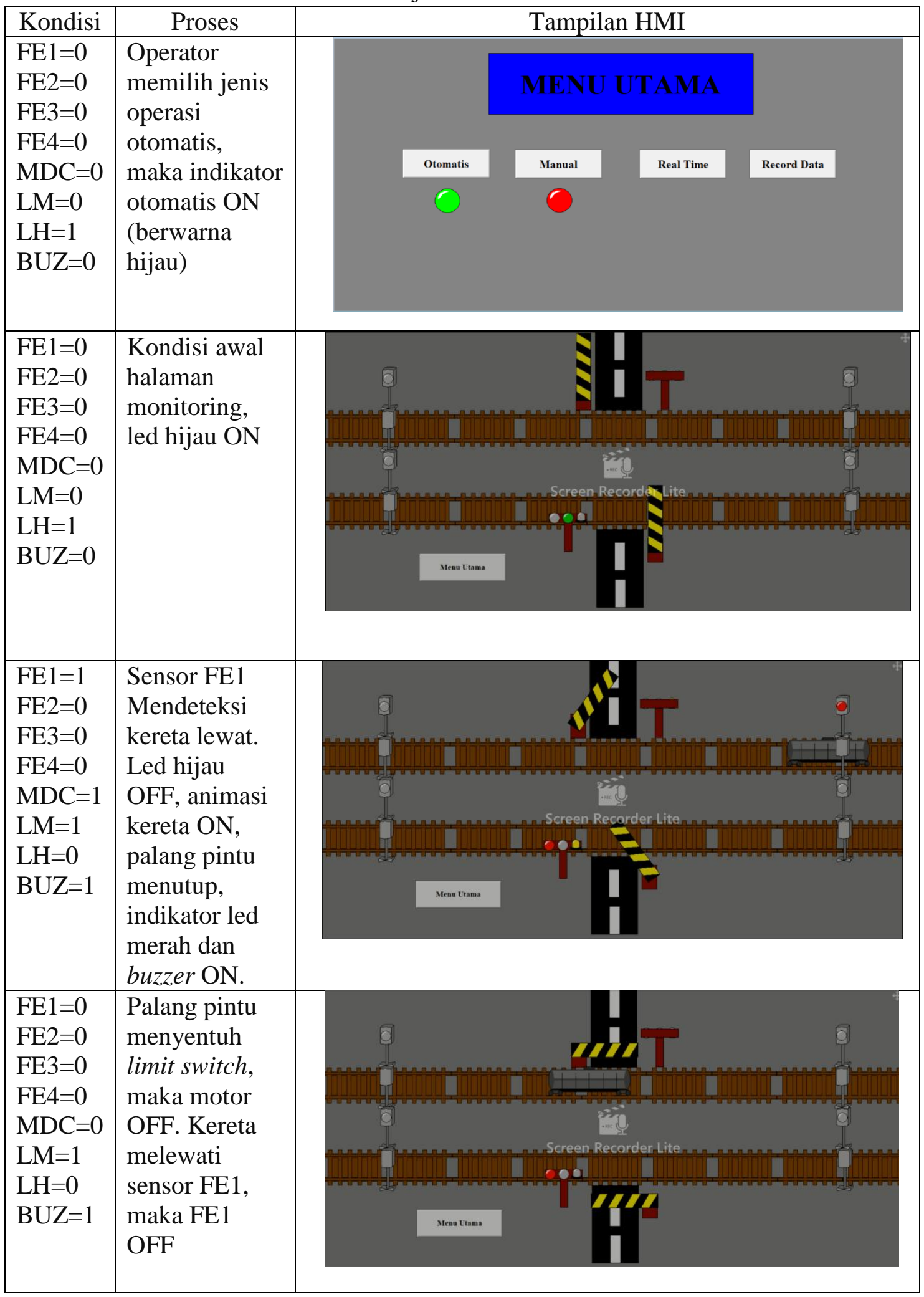


Lanjutan Tabel 3

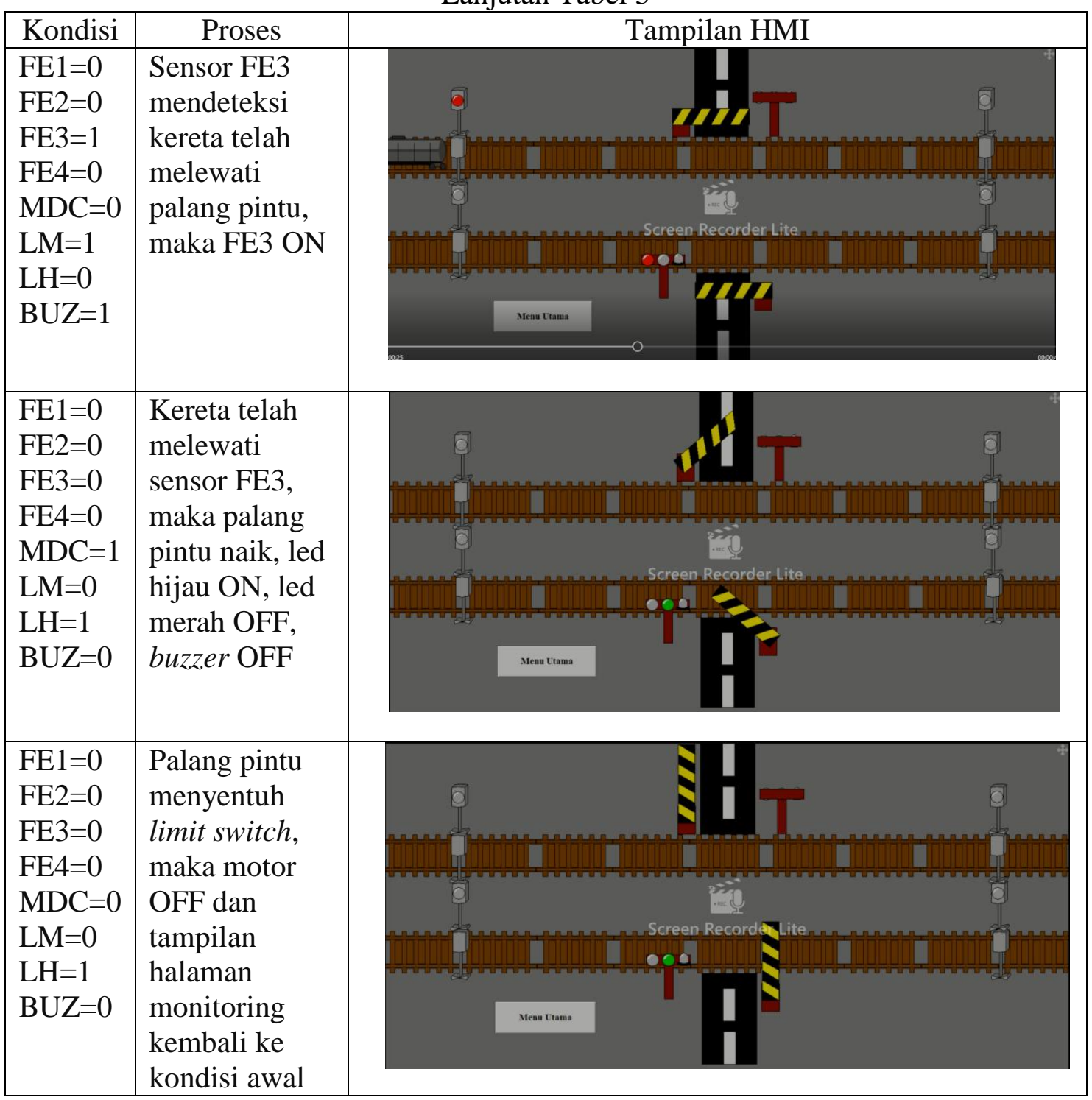

Dari Tabel 3 tampak bahwa saat operator memilih mode operasi otomatis dari HMI, makan led hijau ON. Sistem bekerja ketika sensor FE1 mendeteksi ada kereta akan melintas, dan sistem selesai ketika sensor FE3 mendeteksi kereta telah selesai melintas. Pada saat sensor FE1 mendeteksi kereta akan melintas, palang pintu sudah tertutup penuh sebelum kereta sampai ke palang pintu. Palang pintu terbuka ketika sensor FE3 sudah tidak mendeteksi adanya gerbong kereta dalam waktu 0,2 detik. Berdasarkan hasil pengamatan yang dilakukan pada saat percobaan, hubungan antara tampilan HMI dengan plant sudah baik karena kondisi komponen I/O keduanya sama.

\section{Kesimpulan}

Berdasarkan hasil dan pembahasan prototipe palang pintu kereta api otomatis 2 jalur Berbasis PLC M221 yang telah dilakukan maka dapat disimpulkan:

1. Sistem kendali palang pintu kereta api 2 jalur dapat mendeteksi kereta yang akan lewat maupun yang sudah lewat, dari semua arah (kiri maupun kanan), baik 1 kereta maupun 
2 kereta dengan berbagai macam jumlah gerbong sehingga dapat menggerakkan aktuator (motor palang pintu, alarm dan lampu indikator) sesuai yang diinginkan .

2. Komunikasi antara HMI dengan PLC melalui ethernet sudah berjalan dengan baik sehingga HMI dapat menerima data dari PLC dan dapat menampilkan kondisi sistem secara real time.

\section{Ucapan Terima Kasih}

"Penulis Th. Prima Ari dan Dede Kurniawan Salim mengucapkan terima kasih kepada LPPM USD yang telah memberikan dukungan finansial melalui Hibah Penelitian Intrenal tahun 2019”.

\section{Daftar Pustaka}

[1] [Online]. Available: http://etd.repository.ugm.ac.id/downloadfile/71381/potongan/S1-2014296391-abstract.pdf. [Diakses 25 Oktober 2018].

[2] F. R. Pramono, "Liputan6.com,” PT Liputan6.com, 8 Desember 2015. [Online]. Available: https://www.liputan6.com/news/read/2385064/beginilah-pengaturan-pintu-perlintasankereta. [Diakses 25 Oktober 2018].

[3] C. Ulin, "SCRIBD,"29 Oktober 2017. [Online]. Available: https://www.scribd.com/document/362935493/Apa-Manfaat-SCADA-Bagi-Anda. [Diakses 5 November 2018].

[4] I. "Ndoware," 3 Agustus 2017. [Online]. Available: http://ndoware.com/kelebihanplc.html. [Diakses 25 Oktober 2018].

[5] "Schneider Electric," Schneider Electric, [Online]. Available: https://www.schneiderelectric.com/en/product/TM221CE24R/controller-m221-24-io-relay-ethernet/. [Diakses 25 Oktober 2018].

[6] Firdaus, M. A. (2015). Miniatur Palang Pintu Kereta Api Otomatis dengan Menampilkan Kecepatan Kereta Serta Waktu Tunggu Menggunakan Arduino (Doctoral dissertation, Universitas Negeri Semarang).

[7] F. M. Subali dan D. Nur'ainingsih, (2008). Palang Pintu Kereta Otomatis Dengan Indikator Suara Sebagai Peringatan Dini Berbasis Mikrokontroler AT89S51. Jurnal Teknologi \& Rekayasa, 13(1).

[8] S. Irawan. (2007). Sistem PLC Pada Model Pengatur Palang Pintu Perlintasan Kereta Api Otomatis. 